\title{
Growth status and the risk of contracting primary tuberculosis
}

\author{
R J RONA, S CHINN, B S M MARSHALL, AND M EAMES \\ Department of Community Medicine, St Thomas's Hospital Medical School, London; Leicestershire
District Health Authority
}

SUMMARY A case of open tuberculous infection in a member of staff at a primary school resulted in an outbreak in which nearly a quarter of the children in the school contracted a primary infection. The growth status of these children was compared with that in the non-infected children before the outbreak and on two occasions after the outbreak. The children with tuberculous infection were taller and fatter than the controls before and after the outbreak but differences were not always statistically significant. Among children with a good nutritional status the thin and small child is at no greater risk of contracting primary tuberculous infection than other children.

A tuberculous outbreak in a primary school in Leicestershire allowed us to compare the growth of children with and without primary infection. The episode took place in a school participating in a national surveillance system of growth in England and Scotland. Measurements of height, weight, and triceps skinfolds were available for most children both before and after the tuberculosis outbreak in 1979. The source of the infection in the school was a member of staff whom we suspect had been infectious for 2 months before detection of the outbreak.

So far most of the reports relating physique to tuberculosis have been restricted to young adults undergoing training in the armed forces. ${ }^{1-4}$ These reports have all confirmed the popular notion that tuberculous disease (secondary infection) develops more often in tall and thin men. None of these studies, however, found an association between physique and primary tuberculous infection. This suggests that body build is an important contributor in the pathogenesis of tuberculous disease but is not a barrier to primary infection. These data provide the opportunity to review the relation of growth status and primary infection in a young age group exposed to infection for a short period of time from a precise source.

\section{Material and methods}

The primary school was located in a small town, with a stable population and a low rate of immigration. All children were white and the family socioeconomic status was higher than that in the rest of our study areas, with a very low proportion of families in social class IV or V.
As soon as the source of the infection was ascertained all children in the school were contacted by the school health service. Records for 204 children were available for analysis, and 196 children were present at the 1979 measurement session ( 3 months after the outbreak occurred). Of these children, 161 were measured in 1978 and 155 in 1980.

A Heaf test and a chest $x$-ray film were performed for most children in 1979. According to the intensity of the reaction to the Heaf test children were divided into five groups: zero indicated lack of response and 4 an intense reaction. Results of the chest $x$-ray film were divided into three groups: negative, positive, and query positive. An area of consolidation in the lungs or an enlargement of an intrathoracic gland was identified as a positive result in the chest $x$-ray film.

For the purpose of this paper we have defined a child as having contracted a primary infection if his Heaf test score was 3 or 4 or if his chest $x$-ray film was positive or query positive. As no child in the study had a BCG before 1979 it was not necessary to make allowances for tuberculous immunisation. Table 1 shows the number of children according to Heaf test and chest $x$-ray film. Altogether 15 children were not included in the analysis, 5 for whom neither test was available and 10 children with a Heaf test less than 3 and who were not given a chest $x$-ray film. The total number of children included in the tuberculous group was 46 of whom 43 were treated. Most of the children were treated with a combination of isoniazid and rifampicin. Two of 143 children we classified as free of tuberculous infection received treatment. In the results 
Table 1 Number of children classified by results of Heaf test and $x$-ray film (number treated in brackets)

\begin{tabular}{|c|c|c|c|c|c|c|c|}
\hline \multirow[t]{2}{*}{ Chest $x$-ray film } & \multicolumn{7}{|c|}{ Heaf test score } \\
\hline & 0 & 1 & 2 & 3 & 4 & Not known & Total \\
\hline $\begin{array}{l}\text { Negative } \\
\text { ? Positive } \\
\text { Positive } \\
\text { Not done or not known }\end{array}$ & $\begin{array}{r}126(0) \\
2(0) \\
3(3) \\
9(0)\end{array}$ & $\begin{array}{c}12(1) \\
0 \\
10(10) \\
1(0)\end{array}$ & $\begin{array}{l}5(1) \\
2(2) \\
4(4) \\
0\end{array}$ & $\begin{array}{l}6(6) \\
1(1) \\
7(7) \\
0\end{array}$ & $\begin{array}{l}3(2) \\
0 \\
6(6) \\
0\end{array}$ & $\begin{array}{l}0 \\
0 \\
2(2) \\
5(1)\end{array}$ & $\begin{array}{c}152(10) \\
5(3) \\
32(32) \\
15(1)\end{array}$ \\
\hline Total & $140(3)$ & $23(11)$ & $11(7)$ & $14(14)$ & $9(8)$ & $7(3)$ & 204 (46) \\
\hline
\end{tabular}

section the growth of children with primary infection (cases) will be compared with the growth of children without primary infection (controls).

The anthropometric measurements were taken by trained local nurses supervised by a fieldworker who checked $10 \%$ of the measurements. Height and weight were measured as recommended by Tanner et $a .^{5}$ and triceps skinfolds as described by Tanner et al. ${ }^{6}$ However we measured triceps skinfolds in a position slightly higher up the arm than Tanner and Whitehouse. ${ }^{7}$ The readings were recorded to the last complete $0.1 \mathrm{~cm}$ for height, $100 \mathrm{~g}$ for weight, and $0.2 \mathrm{~mm}$ for triceps skinfold.

Results are expressed in these units for age group analysis while standardised scores were used in analyses in which all children were included. These scores allowed us to remove the effects of age and gender, and to standardise for the increasing variance of the measurements between the ages of 5 and $11 \frac{1}{2}$ years. The standardised score of height was calculated for each child as the difference between his measurement and the average measurement of a population of the same age, gender, and country divided by the standard deviation of the measurement for that population. The expected value for the exact age of the child was calculated using cubic curves fitted to mean values for 6 month age groups. As the distributions of weight and triceps skinfolds were skewed to the right, the data were transformed logarithmically to give a satisfactory Gaussian distribution in each age group. The weight transformation used was $\log _{\mathrm{e}}$ (weight), and the triceps skinfolds (TSF) transformations were $\log _{e}(\mathrm{TSF}-3 \cdot 0)$ for boys and $\log _{\mathrm{e}}(\mathrm{TSF}-1 \cdot 5)$ for girls.

Analysis of variance was used to test differences in growth between the case and control groups. Measures of growth and rate of height gain were used as dependent variables. Change in the standardised score for each child over 1 or 2 years was used as a measure of height gain. This is analogous to change in centile rank over time (see Smith et al. ${ }^{8}$ ).

\section{Results}

Some children in every class contracted primary infection but there were two classes which were especially affected $(65 \%$ in one and $44 \%$ in the other). The children in these two classes were aged 6 and 7 years in 1979 (Table 2). Slightly more boys $(26 \%)$ than girls $(19 \%)$ were infected. There was no suggestion that primary infection was associated with either father's social class, as defined by father's occupation, or number of siblings.

In most classes, children who contracted tuberculous infection were taller before the outbreak and remained taller than the control group in the follow-up period. The differences in height between the case and control groups were tested in the total sample. These were not significant in terms of standardised scores for 1978, 1979, or 1980 (Table 3). As nearly the same children participated each year the results between years are not independent. Changes in standardised height scores for the periods, $1978-79,1979-80$, and $1978-80$ (used as a measure of rate of growth) showed that, as a group, children who contracted tuberculosis were growing faster than the control group. The mean difference was significant for the period 1978-80 but not significant for either the period $1978-79$ or 1979-80.

Weights of cases and controls were compared allowing for height, age, and gender. Children with primary infection were heavier than the controls at the 1979 survey $(P<0.05)$. A similar pattern was observed during the 1978 and 1980 survey but the differences were not significant. The children with primary infection had thicker mean triceps skinfolds in 1978 (pretreatment period) after allowing for age

Table 2 Number of cases of tuberculosis by class (1979)

\begin{tabular}{|c|c|c|c|c|c|}
\hline Class & $\begin{array}{l}\text { Average age } \\
\text { (1979) }\end{array}$ & $\begin{array}{l}\text { Cases } \\
\text { No }\end{array}$ & $(\%)$ & $\begin{array}{l}\text { Incomplete } \\
\text { examination }\end{array}$ & $\begin{array}{l}\text { No children } \\
\text { in class }\end{array}$ \\
\hline 1 & $5 \cdot 4$ & 4 & 17 & 1 & 23 \\
\hline 2 & $6 \cdot 3$ & 17 & 65 & $i$ & 26 \\
\hline 3 & $7 \cdot 3$ & 11 & 44 & 0 & 25 \\
\hline 4 & $8 \cdot 3$ & 4 & 14 & 3 & 28 \\
\hline 5 & $9 \cdot 3$ & 5 & 15 & 1 & 33 \\
\hline 6 & $10 \cdot 3$ & 2 & 6 & 1 & 34 \\
\hline 7 & $11 \cdot 3$ & 3 & 10 & 3 & 30 \\
\hline Total & & 46 & 23 & 10 & 199 \\
\hline
\end{tabular}


Table 3 Mean height and mean change of height in terms of standardised scores for children with and without tuberculous infection

\begin{tabular}{lrrrr}
\hline $\begin{array}{l}\text { Standardised } \\
\text { scores }\end{array}$ & Year & Cases & Controls & $\begin{array}{l}\text { Difference } \\
\text { between cases } \\
\text { and controls } \\
\pm S E\end{array}$ \\
\hline Height & 1978 & $0.29(39)$ & $0.10(115)$ & $\begin{array}{l}0.19+0.19 \\
\end{array}$ \\
& 1979 & $0.35(43)$ & $0.16(138)$ & $0.19+0.17$ \\
& 1980 & $0.36(37)$ & $0.08(110)$ & $0.29+0.20$ \\
Change of & $1978-79$ & $0.06(38)$ & $0.03(111)$ & $0.03+0.03$ \\
height & $1979-80$ & $0.05(35)$ & $-0.03(109)$ & $0.08+0.05$ \\
& $1978-80$ & $0.13(31)$ & $-0.01(84)$ & $0.14+0.07$ \\
\hline
\end{tabular}

and gender. This difference was statistically significant $(P<0.05)$. This difference was found also for the period 1979 and 1980 but was not statistically significant.

\section{Discussion}

The children in this study area have a higher mean height than the mean height of all children participating in the surveillance system in other study areas. This indicates that the nutritional status of children in this school was satisfactory. Our results suggest that the infected children were on average taller and fatter than the non-infected children. While the difference for height was non-significant this pattern was consistently observed for nearly all classes in the school before and after the outbreak. Similarly, mean triceps skinfolds and weight for height were consistently higher in cases than controls during the 3 years. The difference was significant for triceps skinfolds in 1978 and for weight for height in 1979. On the whole the differences were between 1 and $1 \frac{1}{2} \mathrm{~cm}$ in height, $1 \mathrm{~kg}$ in weight after allowing for height, and between 1 and $2 \mathrm{~mm}$ in triceps skinfolds. The differences were fairly large but it was difficult to show them as statistically significant in this small sample.

There are indications that the taller children were more susceptible to tuberculous infection. There is evidence from other studies that the tall are more at risk of contracting a secondary infection but no evidence supporting an association with primary infection status. ${ }^{1-4}$ Contrary to a long standing belief, our results indicate that the cases tended to be fatter than the non-infected children. We believe that the relatively greater heaviness and thicker triceps skinfolds of children with primary infection was not due to the treatment received because these children already had heavier bodies and thicker triceps skinfolds before the outbreak. Our results suggest that in schoolchildren with a good nutritional status the tall and fat child is not protected from primary infection and if anything may be more vulnerable to it.

We are most grateful to the headteacher, his staff, parents, and children of the school in Leicestershire for their continuous collaboration; Professor W W Holland for constant support and encouragement.

The study was funded by the Department of Health and Social Security.

\section{References}

${ }^{1}$ Beckjord P R, Sartwell P E. Epidemiologic study of tuberculosis in the US navy and marine corps. I. Methodology and individual factors. US Armed Forces Med $J$ 1958; 9: 705-27.

2 Edwards L B, Livesay V T, Acquaviva F A, Palmer C E. Height, weight, tuberculous infection, and tuberculous disease. Arch Environ Health 1971; 22: 106-12.

3 Palmer C E, Jablon S, Edwards $\mathbf{P}$ Q. Tuberculosis morbidity of young men in relation to tuberculin sensitivity and body build. Am Rev Respir Dis 1957; 76: 517-39.

4 Reed L J, Love A G. Biometric studies on US army officers: somatological norms in disease. Hum Biol 1933; 5: 61-93.

5 Tanner J M, Whitehouse R H, Takaishi M. Standards from birth to maturity for height, weight, height velocity, and weight velocity: British children, 1965. Part I and II. Arch Dis Child 1966; 41: 454-71, 613-35.

6 Tanner J M, Whitehouse R M. Standards for subcutaneous fat in British children. Percentiles for thickness of skinfold over triceps and below scapula. $\mathrm{Br}$ Med $\mathrm{J}$ 1962; i: 446-50.

7 Rona R J, Altman D G. National study of health and growth: standards of attained height, weight, and triceps skinfold in English children 5 to 11 years old. Ann Hum Biol 1977; 4: 501-23.

8 Smith A M, Chinn S, Rona R J. Social factors and height gain of primary schoolchildren in England and Scotland. Ann Hum Biol 1980; 7: 115-24.

Correspondence to Dr R J Rona, Department of Community Medicine, St Thomas's Hospital Medical School, London SE1 7EH.

Received 27 September 1982 